\title{
Photocatalytic activity under visible light irradiation of cement based materials containing $\mathrm{TiO}_{2-\mathrm{x}} \mathrm{N}_{\mathrm{y}}$ nanoparticles
}

\author{
Actividad fotocatalitica en luz visible de un cemento con adición de nano partículas de \\ $\mathrm{TiO}_{2-\mathrm{x}} \mathrm{N}_{\mathrm{y}}$
}

\begin{abstract}
Jorge I. Tobón (iD ${ }^{1 *}$, Juan D. Cohen (ib ${ }^{1}$, Ludovic Dorkis (1) ${ }^{2}$
${ }^{1}$ Grupo del Cemento y Materiales de Construcción CEMATCO, Facultad de Minas, Universidad Nacional de Colombia. Cra. 65 \# 59 a-110. C.P. 05001000 . Medellín, Colombia.

${ }^{2}$ Grupo Investigación en Catálisis y Nano Materiales, Facultad de Minas, Universidad Nacional de Colombia. Cra. 65 \# 59a-110. C.P. 05001000. Medellín, Colombia.
\end{abstract}

\section{CITE THIS ARTICLE AS:}

J. I. Tobón, J. D. Cohen, L. Dorkis. "Photocatalytic activity under visible light irradiation of cement based materials containing $\mathrm{TiO}_{2-\mathrm{x}} \mathrm{N}_{\mathrm{y}}$ nanoparticles", Revista Facultad de Ingeniería Universidad de Antioquia, no. 94, pp. 87-96, Jan-Mar 2020. [Online]. Available: https://www . doi.org/10.17533/ udea.redin. 20190730

\section{ARTICLE INFO:}

Received: October 30, 2018 Accepted: July 05, 2019 Available online: July 05, 2019

\section{KEYWORDS:}

Self-cleaning cement; nanoparticles of titanium oxynitride $\left(\mathrm{TiO}_{2-x} \mathrm{~N}_{\mathrm{y}}\right)$; photocatalitic activity under visible light; rhodamine $B$ abatement; photocatalysis

Cemento autolimpiante; nanopartículas de oxinitruro de titanio $\left(\mathrm{TiO}_{2-\mathrm{x}} \mathrm{N}_{\mathrm{y}}\right)_{\text {; }}$ actividad fotocatalítica bajo luz visible; decaimiento de rodamina $B$; fotocatálisis
ABSTRACT: Self-cleaning activity of Portland cement pastes blended with nanoparticles of titanium oxynitride $\left(\mathrm{TiO}_{2-x} \mathrm{~N}_{y}\right)$ was studied. Samples with various amounts of $\mathrm{TiO}_{2-x} \mathrm{~N}_{y}$ $(1 \%$ and $3 \%)$ were evaluated under irradiation of UV and visible light, and with two curing ages ( 65 hour and 28 days). Rhodamine B was the pigment used and its loss of color on the cement pastes was carried out using a Spectrometer UV/Vis measuring the coordinates CIE (Commission Internationale de l'Eclairage) $L^{*}, a^{*}, b^{*}$. Discoloration of Rhodamine $B$ on the surface of the samples was established as the photocatalytic efficiency coefficient $(\varepsilon)$. In addition, samples with $\mathrm{TiO}_{2}$ nanoparticles $(1 \%$ and $3 \%)$ were studied under the same conditions and their performances were compared with $\mathrm{TiO}_{2-x} \mathrm{~N}_{\mathrm{y}}$. The presence of nitrogen in the tetragonal structure of $\mathrm{TiO}_{2}$ was evidenced by $\mathrm{X}$-ray diffraction (XRD), ultraviolet-visible diffuse reflectance spectrophotometry and Carbon, Hydrogen and Nitrogen $(\mathrm{CHN})$ analysis. The band gap for $\mathrm{TiO}_{2}$ and $\mathrm{TiO}_{2-x} \mathrm{~N}_{y}$ was determined by the transformed Kubelka-Munk function $\left(\left[F\left(R_{\infty}\right) h v\right]^{1 / 2}\right)$. The results have shown a similar behavior for both additions under UV light irradiation, with 3\% being the addition with the highest photocatalytic efficiency obtained in the early ages of curing time. $\mathrm{TiO}_{2-\mathrm{x}} \mathrm{N}_{\mathrm{y}}$ showed activity under irradiation with visible light, unlike $\mathrm{TiO}_{2}$, which could only be activated under UV light. At the late curing ages, the samples with $3 \%$ of $\mathrm{TiO}_{2-x} \mathrm{~N}_{\mathrm{y}}$ showed the highest efficiency under irradiation of UV and visible light.

RESUMEN: Se estudió la actividad autolimpiante en pastas de cemento Portland adicionadas con nanopartículas de oxinitruro de titanio $\left(\mathrm{TiO}_{2-x} \mathrm{~N} \mathrm{~N}_{y}\right)$. Se evaluaron $1 \%$ y $3 \%$ de $\mathrm{TiO}_{2-x} \mathrm{~N}_{y}$ bajo irradiación de luz UV y visible, a 65 horas y 28 días de curado. Rodamina $B$ fue el pigmento utilizado y su pérdida de color en las pastas se determinó utilizando un Espectrómetro UV / Vis usando las coordenadas CIE (Comisión Internacional de la Eclaral L* $, a^{*}, b^{*}$. La decoloración del pigmento en las muestras se estableció como el coeficiente de eficiencia fotocatalítica $(\varepsilon)$. Además, muestras con nanopartículas de $\mathrm{TiO}_{2}$ $(1 \%$ y $3 \%)$ se estudiaron en las mismas condiciones y sus rendimientos se compararon con los obtenidos con $\mathrm{TiO}_{2-x} \mathrm{~N}_{\mathrm{y}}$. La presencia de nitrógeno en la estructura del $\mathrm{TiO}_{2}$ se evidenció mediante difracción de rayos $X$, espectrofotometría ultravioleta-visible de reflectancia difusa y análisis elemental $\mathrm{CHN}$. La banda prohibida para $\mathrm{TiO}_{2}$ y $\mathrm{TiO}_{2-\mathrm{x}} \mathrm{N}_{\mathrm{y}}$ se determinó mediante la función Kubelka-Munk transformada $\left(\left[F\left(R_{\infty}\right) h v\right]^{1 / 2}\right)$. Los resultados mostraron un comportamiento similar para ambas adiciones bajo irradiación ultravioleta, siendo $3 \%$ la adición con la mayor eficiencia fotocatalítica en las primeras edades de curado. Sin embargo, el $\mathrm{TiO}_{2-x} \mathrm{~N}_{\mathrm{y}}$ mostró actividad bajo irradiación con luz visible, a diferencia del $\mathrm{TiO}_{2}$, que solo fue activo bajo luz UV. A edades de curado tardío, las muestras con $3 \%$ de $\mathrm{TiO}_{2-x} \mathrm{~N}_{y}$ presentaron la mayor eficiencia bajo irradiación de luz UV y visible.

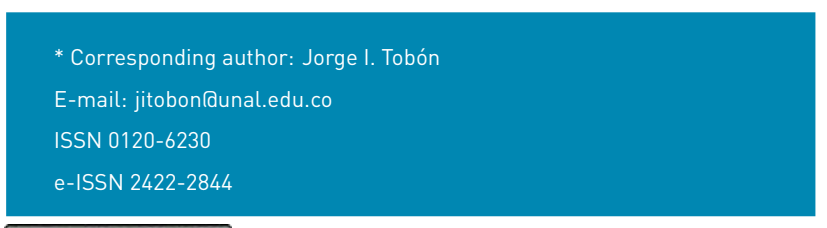




\section{Introduction}

In recent years, the study of photocatalysis has established solid bases for comprehension of the phenomena and has allowed the application of photocatalytic materials in several areas. A recent application is the mixture of photocatalytic solids with building material, which provide a new method for the removal of pollutants from air. This mixture can provide properties such as self-cleaning [1], purification, depollution capacity [2, 3] and self-disinfecting $[4,5]$. Perhaps, the most studied photocatalyst material is the titanium dioxide $\left(\mathrm{TiO}_{2}\right)[6]$, even with a band gap of $3.2 \mathrm{eV}$ (for anatase phase), that makes that $\mathrm{TiO}_{2}$ needs to be activated under ultraviolet light [7].

Numerous papers have reported the influence of $\mathrm{TiO}_{2}$ nanoparticles in cementitious materials to accomplish an auto-cleaning or depollution effect [8-12]. Several of those studies have used Rhodamine B dye as an organic model pollutant to evaluate the auto-cleaning properties. Plassais et al. evaluated the effect of the addition of $\mathrm{TiO}_{2}$ in the photocatalytic properties of cement pastes and mortars [10-12]. They reported that the photocatalytic efficiency was affected by the addition of aggregates which block the absorption of photons, and the increasing of the $\mathrm{TiO}_{2}$ /cement ratio improves the auto cleaning properties [8].

Many studies have concentrated its efforts in changing the band gap of the several photocatalysts [13] reported the modification of the band gap of the $\mathrm{TiO}_{2}$ through a a, $\mathrm{P}^{3-}$.in the anatase $\left(\mathrm{TiO}_{2}\right)$ crystal indicated that $\mathrm{N}^{-3}$ anion was the best dopant species with a reduction of the band gap without increase in the recombination of charge carriers. Than can be explained from Ti-N bonds and its $\mathrm{N}_{p}$ states that mixed with $02 p$ states create electronic states in the prohibited energy stages $[13,14]$. The interesting aspect of this substitution is that it increases the range of the solar spectrum absorption [15]. Other authors have suggested that it is possible to produce $\mathrm{TiO}_{2-x} \mathrm{~N}_{y}$ particles with the property to absorb wavelengths between $365 \mathrm{~nm}$ and $500 \mathrm{~nm}[16,17]$. Amadelli et al. [18-20] reported the photocatalytic performance of $\mathrm{TiO}_{2-x} \mathrm{~N}_{y}$ in constructions materials. This mixture has the capacity of reducing the $\mathrm{NO}_{\mathrm{x}}$ and 2-propanol using wavelengths between 360 and $436 \mathrm{~nm}$.

The aim of this manuscript is to report the effect of $\mathrm{TiO}_{2-x} \mathrm{~N}_{y}$ nanoparticles blended in the Portland cement, in order to evaluate their auto-cleaning abilities under UV-vis irradiation. Rhodamine B was used as a pollutant model and early and late curing ages (65 hours and 28 days), and different addition percentages (1\% and 3\%) were evaluated. A very important aspect is the reporting of the photocatalytic activity under visible light.

\section{Experimental design}

\subsection{Characterization of the materials}

Commercial Portland white cement type I. Graded sand (U.S. Silica Company, Ottawa, IL) conforms to ASTM C778 designation, was used to prepare the mortar cubes. Commercial references of Titanium Oxynitride $\left(\mathrm{TiO}_{2-x} \mathrm{~N}_{\mathrm{y}}\right)$ and Titanium Dioxide $\left(\mathrm{TiO}_{2}\right)$ nanoparticles were acquired from NaBond Technologies Co Chinese company (Shenzhen, China) and the Evonik-Degussa German company (Essen, Germany) respectively. The Titanium Dioxide $\left(\mathrm{TiO}_{2}\right)$ used is known as Aeroxide P25. Rhodamine B (Codim, Colombia) was used as dye.

The cement and photocatalysts materials were characterized by powder X-ray diffraction (XRD) using a PANalytical X'Pert PRO MPD diffractometer with $\mathrm{CuK}_{\alpha 1}=$ 1.5406 and $\mathrm{CuK}_{\alpha 2}=1.5439 \AA$, operated at $45 \mathrm{kV}$ and $40 \mathrm{~mA}$. The diffraction patterns were recorded in the $2 \theta$ values range $4-70^{\circ}$ with a step size of $0.013^{\circ}$ and 59 seconds per step.

Rietveld refinement was performed by using the software MAUD (Materials Analysis Using Diffraction) [21]. Crystallographic data of anatase and rutile were taken from COD (Crystallographic Open Database) [22]. The diffuse reflectance UV-vis spectra (DRS) were recorded at room temperature using a Thermo Scientific EVOLUTION 600 spectrophotometer equipped with an integrating sphere and $\mathrm{BaSO} 4$ was used as a reference. The band gap of $\mathrm{TiO}_{2}$ and $\mathrm{TiO}_{2-\mathrm{x}} \mathrm{N}_{\mathrm{y}}$ was calculated by using the Kubelka-Munk (K-M) transformed function. CHN (Carbon, hydrogen and nitrogen) analysis was carried out on a Truspec LECO CHN analyzer.

\subsection{Preparation and analysis of the samples}

The samples were prepared using white cement paste into an acrylic disc of $16.2 \mathrm{~mm}$ of diameter and a $3 \mathrm{~mm}$ of thickness. The nanoparticles were dispersed into a solution of deionized water with a dispersion agent (superplasticizer based on modified polycarboxylate polymer). The suspension was sonicated at $90 \mathrm{~W}$ and $35 \mathrm{kHz}$ frequency $\left(\mathrm{VWR}^{\circledR}{ }^{\circledR}\right.$ Symphony $^{\mathrm{TM}}$ 97043-992) during $15 \mathrm{~min}$. After that, cement was added to the aqueous suspension in a water/binder ratio of 0.5 and manually mixed. The $\mathrm{TiO}_{2-x} \mathrm{~N}_{y}$ photocatalyst was added in three different concentrations ( $1 \%$ and $3 \%$ ), and $\mathrm{TiO}_{2}$ was added in two concentrations ( $1 \%$ and $3 \%)$. The cement paste was cast at room temperature into disc-shaped molds for the preparation of the samples and were cured for 65 hours 
and 28 days in a wet room at $96 \pm 2 \mathrm{RH}$. Following the standard UNI $11259[23,24]$, the samples were immersed in aqueous solution $0.5 \mathrm{~g} / \mathrm{L}$ of Rhodamine $\mathrm{B}$ during one hour, in order to guarantee a uniform color.

A compressive strength test of cement mortars of 50 $\mathrm{mm}$ was performed according to the ASTM C109 standard [25]. Two sets of samples were prepared with $3 \%$ of $\mathrm{TiO}_{2}$ and $\mathrm{TiO}_{2-\mathrm{x}} \mathrm{N}_{\mathrm{y}}$ respectively, and a third set as a control sample was used. The mortars were fabricated using a water/binder ratio of 0.485 and sand/cement ratio of 2.75 . The tests were performed after 7 and 28 days of curing.

Photocatalytic activity was evaluated in an experimental setup consisted of a UV lamp emitting a wavelength spectrum between 350 and $400 \mathrm{~nm}$ (Actinic BL TL-D(K) 30 W, Phillips, Amsterdam, The Netherlands), with an intensity of $20.0 \pm 0.3 \mathrm{~W} / \mathrm{m}^{2}$ at the position of the specimens as suggested in the standard [24]. The Rhodamine $B$ degradation was measured under visible light, a fluorescent lamp with a wavelength spectrum between 410 and $560 \mathrm{~nm}$ (Lite-Way, C13101, 24 W), and an irradiance of $10.0 \pm 0.5 \mathrm{~W} / \mathrm{m}^{2}$ at the position of the samples was used. The best distance between the lamp and the samples was adjusted with a radiometer (PMA 2210, Solar Light Co., Philadelphia, PA). After 65 hours and 28 days of curing, the samples were exposed to UV and visible lights during 5 hours, in order to evaluate the self-cleaning ability. This photoactinic quality was determined by the disappearance of Rhodamine $B$, which was evidenced by the color changes of the samples. The measurements of the color with the coordinates $L^{*} a^{*} b^{*}$ given by CIE (Commission Internationale de l'Eclairage] [26], were performed in a UV/Vis TE Cooled CCD Spectrometer (BWTEK Inc., Newark, NJ, Glacier ${ }^{T M}$ $X, B T C 112 E)$. The Spectrometer was coupled with a probe for measuring reflection and backscatter (Ocean Optics, QR200-7-UV-VIS) and a support to hold it at a $45^{\circ}$ angle to the samples (Ocean Optics, Dunedin, FL, RPH-1).

\section{Results and discussion}

\subsection{X-ray diffraction (XRD)}

The crystal structures of $\mathrm{TiO}_{2}$ and $\mathrm{TiO}_{2-x} \mathrm{~N}_{y}$ were investigated by X-ray diffraction. All the materials were crystallized in a tetragonal symmetry and the anatase and rutile phases were observed by Rietveld refinement (Figure 1 and 2). The P25 showed $89.55 \%$ of anatase and $10.44 \%$ of rutile while the $\mathrm{TiO}_{2-x} \mathrm{~N}_{y}$ presented $87.56 \%$ of anatase and $12.43 \%$ of rutile. A detailed examination of the diffraction patterns revealed that the crystalline structure changed with the insertion of nitride ions. According the data published in Shannon's table [27], the effective ionic radius for $0^{2-}(1.4 \AA)$ was similar to the ionic radius of $\mathrm{N}^{3-}(1.5 \AA)$ facilitating anion substitution inside the $\mathrm{TiO}_{2}$ structure. However, it is possible that the presence of nitride ions in the interstices modified the cell size; this effect could be observed in the shift of the peaks in Figure 1. Di Valentin et al. have reported that $\mathrm{N}^{3-}$ induces occupied electronic states on intervals known as the forbidden energy band (band gap) [14]. This process can facilitate the generation of the charge carrier (electron-hole pairs), using electromagnetic radiation of wavelengths greater than $400 \mathrm{~nm}$. Figure 2 shows the adjustment obtained by Rietveld for quantification of the phases into $\mathrm{TiO}_{2-\mathrm{x}} \mathrm{N}_{\mathrm{y}}$.

\subsection{Characterization reflectance spectroscopy (DR UV-Vis)}

Figure 3 shows the diffuse reflectance UV-vis spectra of P25 $\left(\mathrm{TiO}_{2}\right)$ and $\mathrm{TiO}_{2-x} \mathrm{~N}_{\mathrm{y}}$. It can be observed that titanium oxynitride presented an increased absorption between 400 and $510 \mathrm{~nm}$, in comparison to $\mathrm{TiO}_{2}$. This evidence suggests that nitride ion is able to modify the optical properties of $\mathrm{TiO}_{2}$, as reported in other works $[13,14]$. The band gap of the nanoparticles was calculated using the reflectance data with the transformed K-M function ( $\left.(F(\text { Rinf }) h v)^{1 / 2}\right)$, as presented in the plot inset of Figure 3. The band gap values obtained for $\mathrm{TiO}_{2}$ and $\mathrm{TiO}_{2-x} \mathrm{~N}_{y}$ were $3.1 \mathrm{eV}$ and 3.02 $\mathrm{eV}$ respectively. Additionally, a second absorption edge was observed in the inset plot at $2.25 \mathrm{eV}(550 \mathrm{~nm})$, which could be attributed to the presence of an energy band located above the valence band that induces the visible light activity as reported by other authors [18].

\subsection{Chemical composition analysis}

Table 1 shows the results of atomic percentage of nitrogen (CHN analysis) for the evaluated nanoparticles. The atomic percentage of nitrogen is necessary, in order to determine the dopant degree of the $\mathrm{TiO}_{2-\mathrm{x}} \mathrm{N}_{\mathrm{y}}$.

Table $1 \mathrm{CHN}$ analysis of $\mathrm{TiO} 2$ and $\mathrm{TiO}_{2-x} \mathrm{~N}_{y}$

\begin{tabular}{ll}
\hline Photocatalyst & Atomic $\% \mathbf{N}$ \\
\hline $\mathrm{P} 25\left(\mathrm{TiO}_{2}\right)$ & 0 \\
$\mathrm{TiO}_{2-\mathrm{x}} \mathrm{N}_{\mathrm{y}}$ & 0.33 \\
\hline
\end{tabular}

Previous works [13] have reported that lower values of nitrogen in $\mathrm{TiO}_{2-x} \mathrm{~N}_{y}$, do not show significant changes in the band gap. However, this condition produces the formation of an isolated narrow band above the valence band, which generates the visible light sensitive photocatalyst. Additionally, the quantic yield of $\mathrm{TiO}_{2-x} \mathrm{~N}_{y}$, when is irradiated with visible light, decreases for higher nitrogen values. This is explained by an increase of the oxygen vacancies, which produces a higher rate of charge 


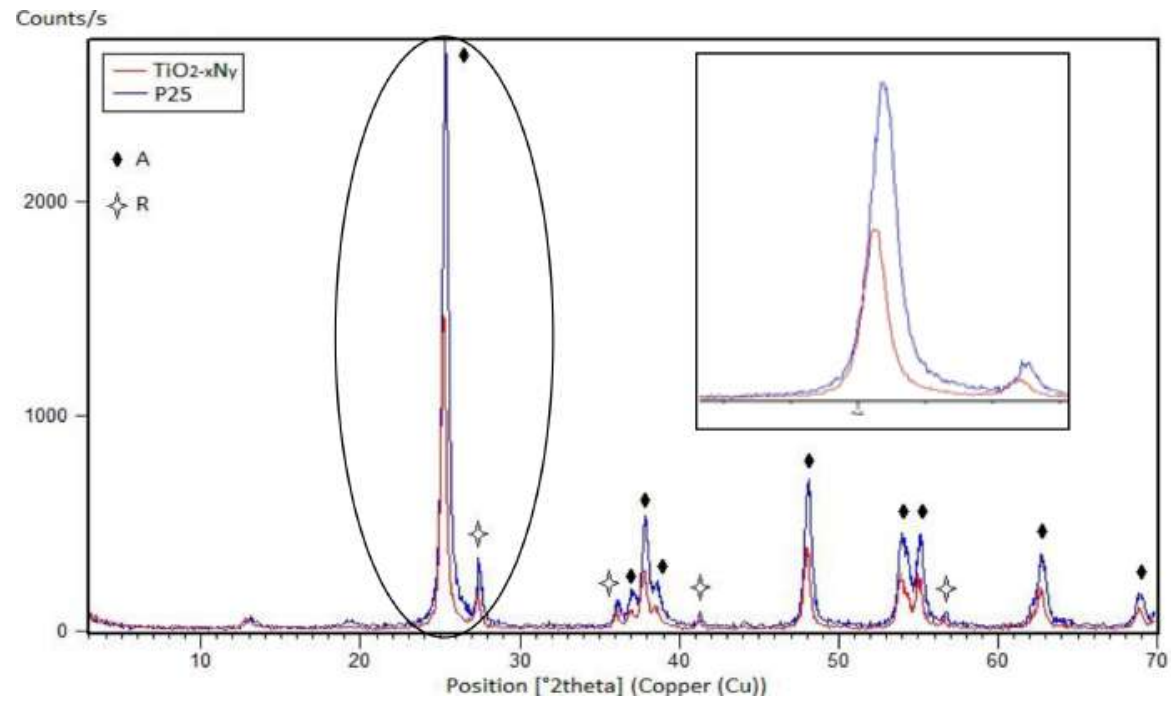

Figure 1 X-ray diffraction (XRD) patterns of Aeroxide P25 $\left(\mathrm{TiO}_{2}\right)$ vs. $\mathrm{TiO}_{2-x} \mathrm{~N}_{\mathrm{y}}$; phases anatase (A) and rutile (R)

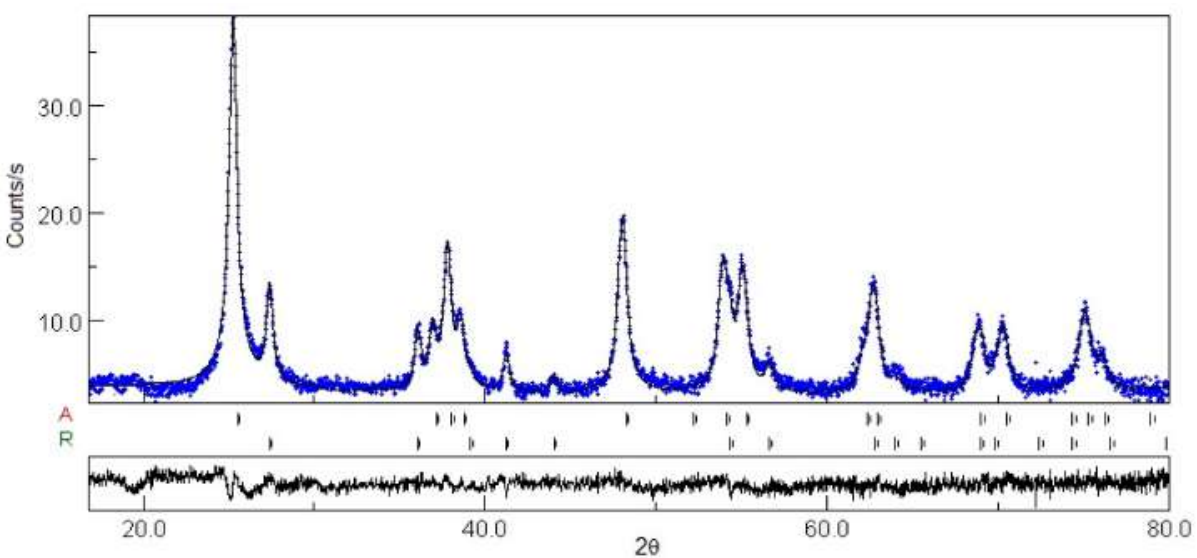

Figure 2 Quantification of the phases obtained by Rietveld method of $\mathrm{TiO}_{2-x} \mathrm{~N}_{\mathrm{y}}$; Anatase (A), Rutile (R); $\mathrm{Rwp}=0.2122$

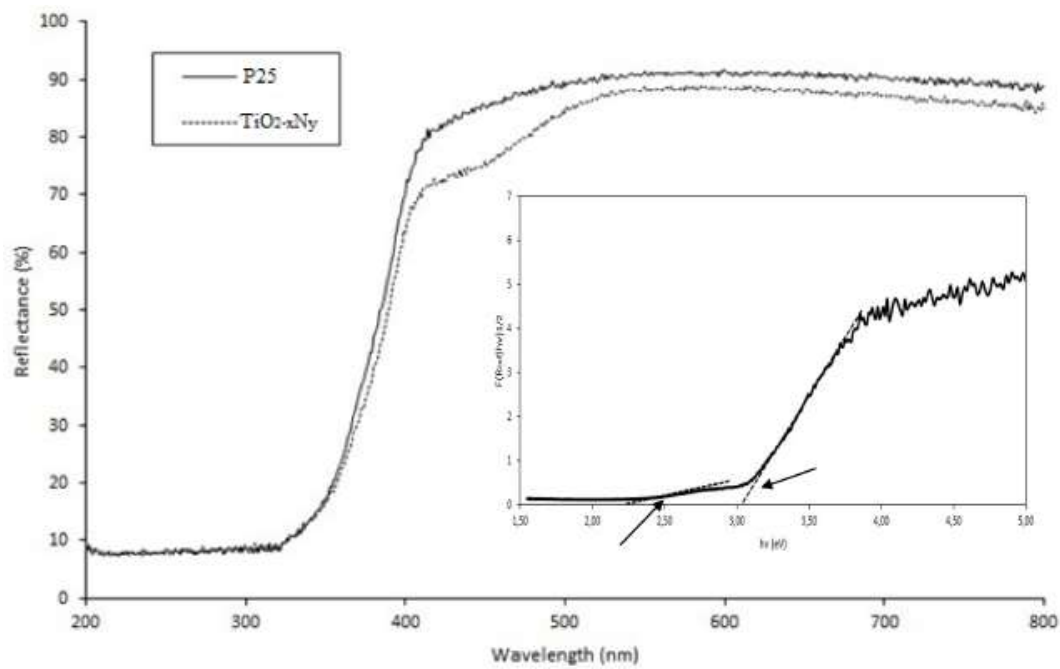

Figure 3 Diffuse reflectance UV-visible spectra of $\mathrm{TiO}_{2}$ and $\mathrm{TiO}_{2-x} \mathrm{~N}_{\mathrm{y}}$. Inset: transformed Kubelka-Munk function (F(Rinf)hv) $)^{1 / 2}$ ) versus the energy of the absorbed light 
carrier recombination.

Figure 4 shows an SEM micrograph with EDS of Portland cement blended with $3 \%$ of $\mathrm{TiO}_{2-x} \mathrm{~N}_{y}$. The selected area shows in purple color the location of the titanium from nanoparticles in the surface of the cementitious matrix. It is noted that the distribution of the nanoparticles in the samples is quite uniform for a $3 \%$ concentration of admixture; therefore, there is an increased probability of it being involved in the photocatalytic reactions.

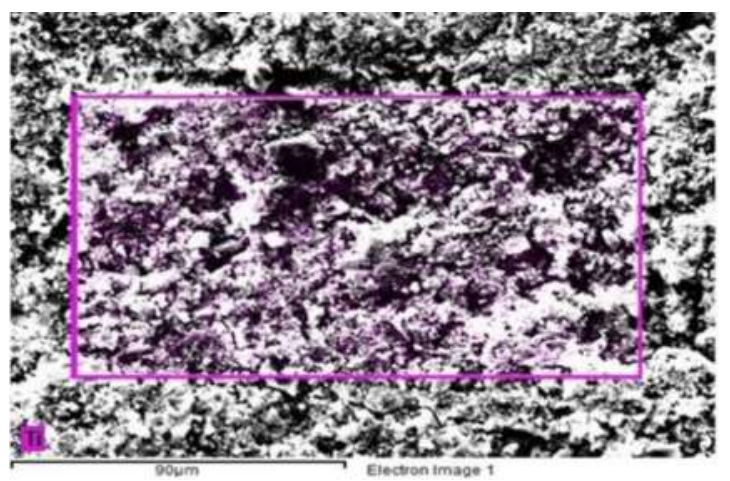

Figure 4 SEM micrograph of Portland cement blended with 3\% of $\mathrm{TiO}_{2-x} \mathrm{~N}_{y}$. Purple color represents titanium

EDS results of the sample of Portland blended with $3 \%$ of $\mathrm{TiO}_{2-x} \mathrm{~N}_{y}$ are shown in Table 2. A significant percentage of nanoparticles in the surface represented by the content of Ti can be observed.

Table 2 EDS quantification of elemental mapping

\begin{tabular}{llll}
\hline Element & An & Weight (\%) & Atomic (\%) \\
\hline $\mathrm{O}$ & 8 & 39,56 & 54,79 \\
$\mathrm{Mg}$ & 12 & 0,31 & 0,28 \\
$\mathrm{Al}$ & 13 & 1,7 & 1,39 \\
$\mathrm{Si}$ & 14 & 6,79 & 5,35 \\
$\mathrm{Ca}$ & 20 & 35,64 & 19,7 \\
$\mathrm{Ti}$ & 22 & 3,85 & 1,78 \\
\hline- & Totals & 126,64 & 99,98 \\
\hline \multicolumn{4}{l}{ An: Atomic number }
\end{tabular}

\subsection{Evaluation of the photocatalytic properties}

Some authors have reported that the photocatalytic degradation of organic dyes using visible light is focused on dye sensitized photocatalytic technology [28]. In this mechanism the dye absorbs photons and transfer electrons to the conductive band of the semiconductor to generate oxidant species. However, this technology depends on certain conditions and factors as the nature of the dye and the catalyst. Other authors have reported photoresponse under visible light by the modifying the
$\mathrm{TiO}_{2}$ [13]. Despite this, it is possible to have a synergistic effect of both cases.

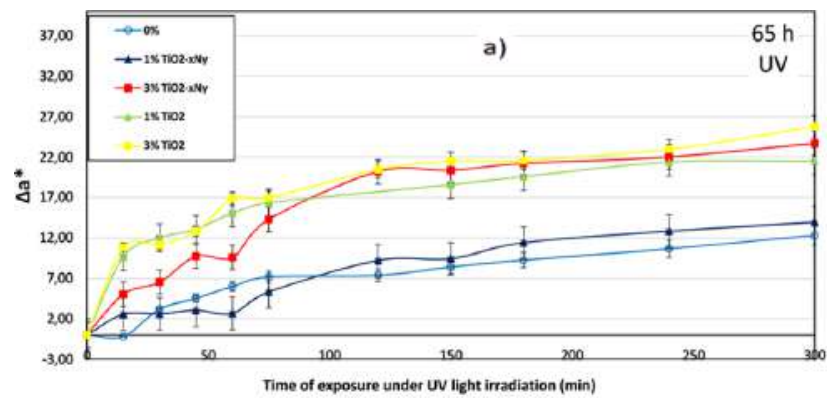

(a)

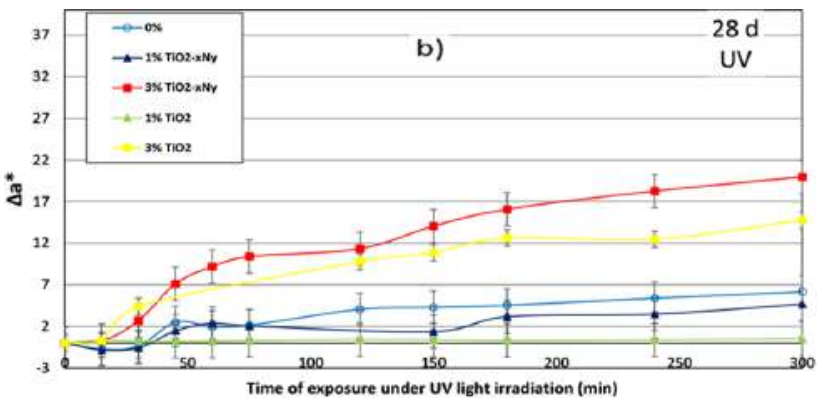

(b)

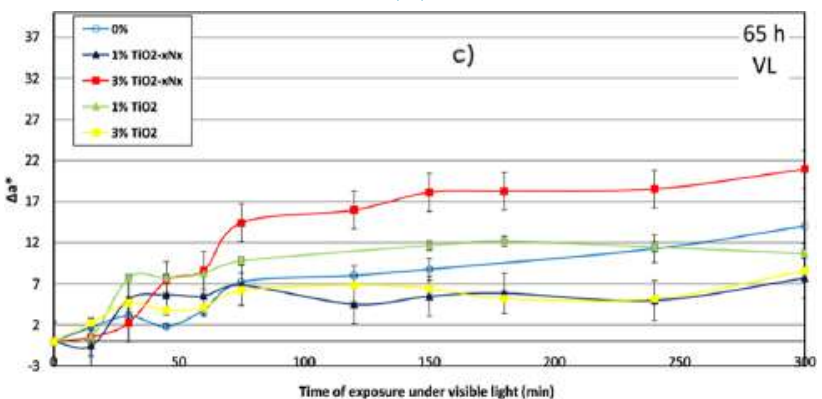

(c)

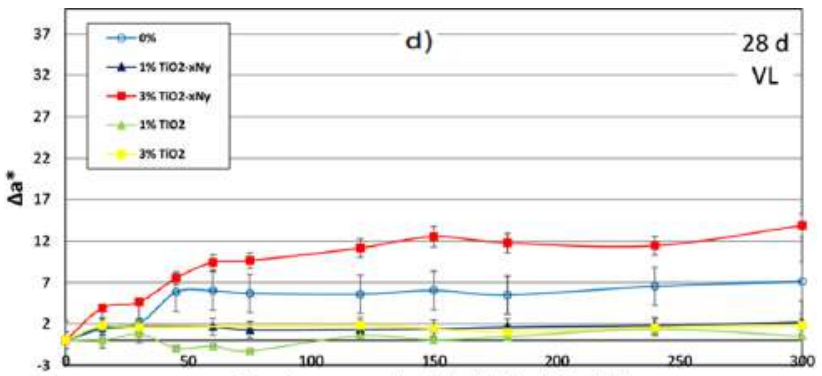

Time of exposure under visible light irradiation (min)

(d)

Figure 5 Change in coordinate $a^{*}$ for the samples exposed to 5 hours of irradiation; al and b) correspond to exposition under UV light irradiation; cl and d) correspond to exposition under visible

light irradiation. al and c) correspond to results for samples after 65 hours of curing age, and b) and d) correspond to results for samples after 28 days of curing age

The discoloration of the specimens was followed by the decrease of the coordinate $a^{*}$ which represents the 
concentration of the dye. The Commission Internationale de l'Eclairage [26] specify a color order system in coordinates where $L^{*}$ represents the brightness, $a^{*}$ the hues from green to red, and $b^{*}$ the hues from blue to yellow. In this case, the Rhodamine $B$ is a reddish hue represented by positives values of the coordinate $a^{*}$. Figure 5 corresponds to the change in $\triangle a^{*}\left(a_{0}{ }^{*}-a_{t}{ }^{*}\right)$ from an initial coordinate $\left(a_{0}{ }^{*}\right)$ until a coordinate with a time of exposure defined as $\left(a_{t}^{*}\right)$. Additionally, the discoloration is represented by an increase of $\triangle a^{*}$ after a period of time under light irradiation. Figure $5 a$, shows the abatement of Rhodamine B in the samples under UV irradiation and curing time of 65 hours. The increase of the nanoparticles in the specimens improve the photoactivity, similarly to reported by some authors [11, 12]. In the same way, the results showed that $\mathrm{TiO}_{2-x} \mathrm{~N}_{y}$ and $\mathrm{TiO}_{2}$ have a similar photocatalytic activity under UV irradiation. In order to exclude other phenomena as photolysis in the specimens, control samples were evaluated to the same conditions. Moreover, Figure $5 c$ shows the behavior of the samples after 65 hours of curing age, under visible light irradiation. The results were quite different with respect to UV light. P25 did not show photoactivity in visible light, possibly to the fact that only can be activated by wavelengths localized in the UVA radiation. In the same way, the highest content of $\mathrm{TiO}_{2-\mathrm{x}} \mathrm{N}_{\mathrm{y}}(3 \%)$ showed better results for the disappearance rate of Rhodamine $\mathrm{B}$ under visible light, confirming the data observed in Figure 3.

Figures $5 b$ and $5 d$ correspond to the results obtained after 28 days of curing age. The specimens showed a loss of photoactivity, which can be associated to the formation of hydrated products from the cement around the nanoparticles and a densification of the matrix, which decreases the amount of light that can enter the cement paste. Despite this, the titanium oxynitride showed better results than $\mathrm{TiO}_{2}$ even under UV light irradiation, according to Figure $5 \mathrm{~b}$. This phenomenon is possibly due to the fact that $\mathrm{TiO}_{2-x} \mathrm{~N}_{y}$ has the ability to capture photons of lower energy as a product of the collision with hydrated products of the cement and calcite. Similar to the results with visible light after 65 hours of curing age, titanium oxynitride obtained a better efficiency in comparison to that of $\mathrm{TiO}_{2}$ under visible light irradiation, especially to higher percentages of addition.

In order to quantify the percentage of decrease in color, a photocatalytic efficiency coefficient $(C)$ was calculated based on a calculation of percentage of difference. That is defined in Equation 1:

$$
C=\frac{A\left(a_{0}^{*}\right)-A\left(a^{*}\right)}{A\left(a_{0}^{*}\right)} \times 100
$$

Where $A\left(a_{0}{ }^{*}\right)$ corresponds to the initial coordinate of each experiment. This value is theoretical and is considered as a reference area, defined by the rectangle of length $t_{f}$ (final time of exposure, $5 \mathrm{~h}$ ) and height $a_{0}{ }^{*}$ (coordinate $a^{*}$ at $\mathrm{t}_{0}$, initial time of the test). At the same time, $A\left(a^{*}\right)$ is defined as the area under the curve $a^{*}(\mathrm{t})$ between $t_{0}$ and $t_{f}$, as mentioned above. The smaller the areas represent the higher the discoloration of the pigment in the specimens. This effect is attributed to physical and/or chemical phenomena, including photocatalysis, photolysis, thermolysis, among others [11]. In this case, the values of $A\left(a^{*}\right)$ were calculated using the trapezium method. It is noted that materials containing photocatalysts will have an accelerated decrease of $A\left(a^{*}\right)$ when irradiated; a product of the synergistic effect of photocatalytic processes and other mechanisms cited. In order to differentiate the photocatalytic activity from other phenomena that participate in the discoloration process in the samples, it was determined a photocatalytic activity coefficient $(\Gamma)$, based on previous works $[11,29,30]$. It is defined in Equation 2:

$$
\Gamma=C-C_{0}
$$

Where $\mathrm{C}_{0}$ corresponds to the photocatalytic efficiency coefficient obtained from the specimens without the photocatalyst (control samples). Similarly, C corresponds to the photocatalytic efficiency coefficient of each of the samples with nanoparticles. It is noted that when photocatalytic activity participates in the decreasing of the color, the values of $\Gamma$ are higher than zero. In the opposite case, other processes are considered in the Rhodamine $B$ disappearance. The results obtained are shown in Figure 6.

In Figure $6 a$, the results of $\Gamma$ obtained for samples after 65 hours of curing age under irradiation with UV light can be observed. It is noted that all the specimens with an addition of nanoparticles showed photoactivity under this type of irradiation. In the same way, $\mathrm{TiO}_{2}$ showed higher photocatalytic activity in respect to the others. This result was expected because $\mathrm{TiO}_{2}$ is highly efficient in the UVA region, and the self-cleaning ability improved directly with the increase of photocatalyst content in the cement, as reported in other research [11, 12]. On the other hand, $\mathrm{TiO}_{2-\mathrm{x}} \mathrm{N}_{\mathrm{y}}$ showed a similar behavior to $\mathrm{TiO}_{2}$ with slightly lower results. In this case, the increase in the generation of active sites seems to be the most important factor for the $3 \%$ of admixture. Therefore, the degradation of Rhodamine B was improved. Furthermore, Figure 6c shows the results of photoactivity under irradiation visible light irradiation. A dormancy for $\mathrm{TiO}_{2}$ in the samples was evidenced by a decrease in the photoactivity respect to the control samples. This phenomenon may be attributed to the fact that the band gap of $\mathrm{TiO}_{2}$ does not allow for electronic jump absorbing photons with low energy (hv $<$ $3.1 \mathrm{eV})$. On the other hand, $\mathrm{TiO}_{2-\mathrm{x}} \mathrm{N}_{\mathrm{y}}$ showed the highest photoactivity with the $3 \%$ additive. The low photoactivity showed by the specimens with $1 \%$ of $\mathrm{TiO}_{2-x} \mathrm{~N}_{y}$ is probably 


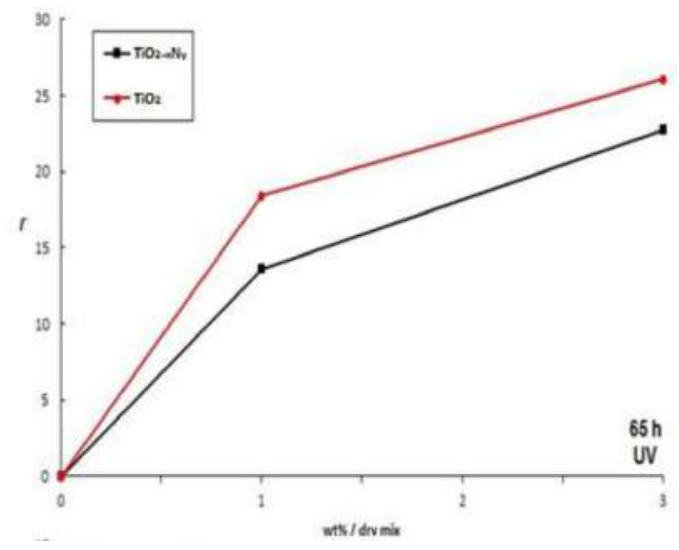

(a)

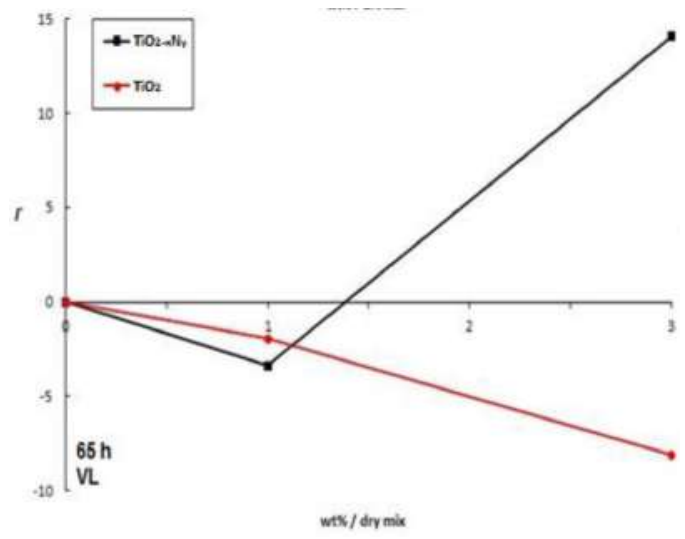

(c)

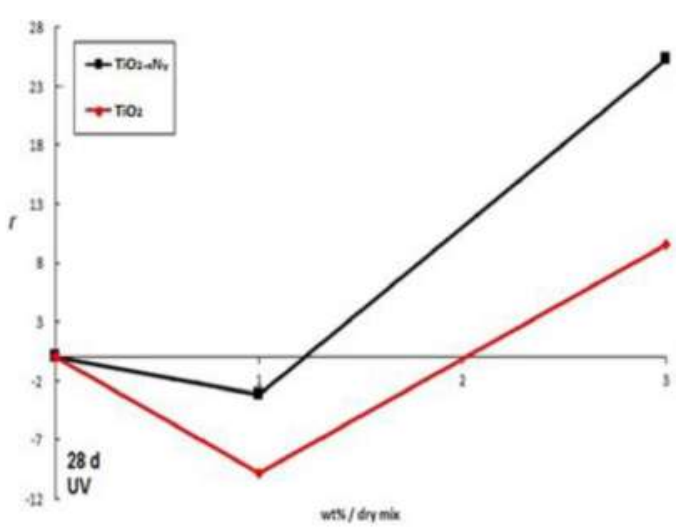

(b)

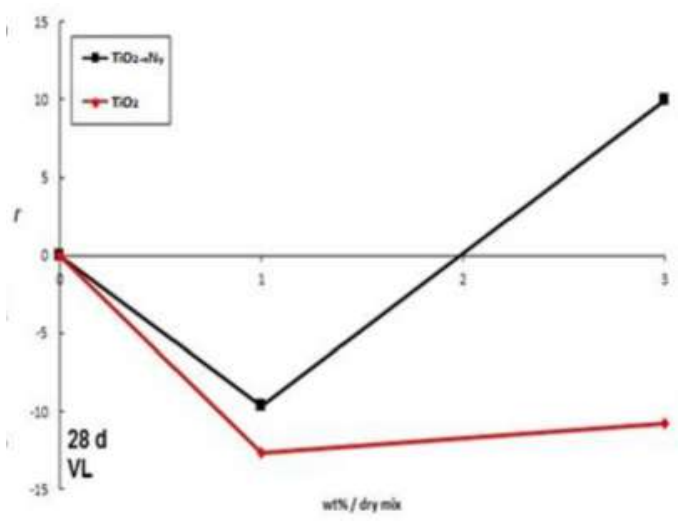

(d)

Figure 6 Photocatalytic activity coefficient vs content of $\mathrm{TiO}_{2}$ and $\mathrm{TiO}_{2-x} \mathrm{~N}_{\mathrm{y}}$. a) and c) 65 hours of curing age; b) and d) 28 days of curing age. The upper charts correspond to results under UV irradiation, and the lower charts correspond to results under visible

associated to the characteristics of the nanoparticles evaluated. The results suggest that the dopant degree is a factor key in the improvement of the efficiency under visible light. In this case, it was observed that the low content of nitrogen was offset by the increase of $\mathrm{TiO}_{2-x} \mathrm{~N}_{y}$ content in the samples.

Figure $6 b$ corresponds to the photoactivity of the specimens after 28 days of curing age, under UV light irradiation. A decrease of performance in each sample with respect to results obtained in Figure ba was observed. To late curing ages (28 days) under UV and visible irradiation (Figures $6 \mathrm{~b}$ and $6 \mathrm{~d}$ ), the specimens showed a loss of photocatalytic activity related to the increase of hydrated products (calcium silicate hydrated and calcium hydroxidel in the cementitious matrix. Moreover, some authors [8, 12] have reported the loss of photoactivity of $\mathrm{TiO}_{2}$ added to the cement after 28 days of curing age. They reported that the nanoparticles improve the hydration process of the cement acting as nucleation sites and increasing the accumulation of calcium silicate hydrated and calcium hydroxide [31]. Possibly, these products gradually bond to the nanoparticles forming a coating on the surface, which obstructs the capture of photons and decreases the photocatalytic activity [32]. However, it was found that the specimens with $3 \%$ of $\mathrm{TiO}_{2-x} \mathrm{~N}_{y}$ obtained a significant photocatalytic activity even after 28 days of curing age under UV irradiation. This result can be explained by taking as a base the low rate of capture of high-energy photons (hv $>3.1 \mathrm{eV}$ ) by the nanoparticles in hydrated cement products $[12,31]$, and by the differences in optical properties between $\mathrm{TiO}_{2}$ and $\mathrm{TiO}_{2-x} \mathrm{~N}_{\mathrm{y}}$. The presence of $2 \mathrm{p}$ orbitals of nitrogen linked to $2 p$ orbitals of oxygen molecules generates electronic states in the bandgap [14], which allows the capture of low energy photons by $\mathrm{TiO}_{2-x} \mathrm{~N}_{y}$ that carry out photocatalytic processes. This phenomenon is observed in Figure $6 \mathrm{~b}$ for the samples with $3 \%$ of $\mathrm{TiO}_{2-x} \mathrm{~N}_{y}$. Photons with wavelengths between 360 and $400 \mathrm{~nm}$ collide directly with the hydrated cement products or pollution molecules, thus decreasing their energy and being absorbed by nanoparticles of $\mathrm{TiO}_{2-x} \mathrm{~N}_{y}$. The semiconductor is excited and generates charge carriers that participate in redox reactions with adsorbed species. In this case, the holes are 
captured by water or $\mathrm{OH}$ - groups forming surface hydroxyl radicals, which are highly reactive with most organic molecules. Through hydrogen abstraction reactions or by addition to aromatic rings, hydroxyl radicals promote the oxidation of substrates by the formation of free radicals, which react readily with oxygen, eventually fragmenting and reaching the complete mineralization. In Figure 6b, it is noted that the addition of $\mathrm{TiO}_{2-x} \mathrm{~N}_{y}$ to the cement demonstrates the possibility of effectively improving the self-cleaning process and the useful life. Once again, it was demonstrated that photoactivity is enhanced by the presence of nitride ions in the atomic structure of $\mathrm{TiO}_{2}$.

In Figure 6d, photoactivity obtained after 28 days of curing age and under visible light irradiation can be observed. It is noted that the results obtained are lower than Figure 6c. This decrease in photocatalytic activity is probably the same phenomenon that occurred in Figure $6 b$, with the difference of the photonic source used. In this case, the visible light corresponds to photons with lower energy in comparison to UV light.

The gradual degradation of the dye is illustrated in the photos shown in Figure 7 . Specimens with $3 \%$ of $\mathrm{TiO}_{2-x} \mathrm{~N}_{y}$ showed a higher self-cleaning property under UV-vis irradiation with respect to the control samples $(0 \%)$.

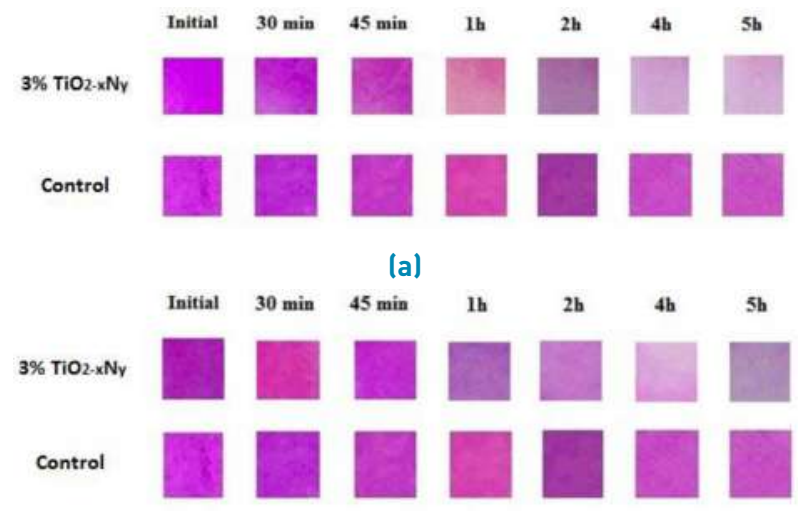

(b)

Figure 7 Photographs of the evolution of the samples with $3 \%$ of $\mathrm{TiO}_{2-x} \mathrm{~N}_{y}$ and comparison with the control sample with pure cement under a) UV and b) visible light irradiation

\subsection{Compressive strength}

Figure 8 shows the compressive strength of mortars cured after 7 and 28 days, evaluating the mechanical behavior of the cement with the two admixtures compared to the control sample. After 28 days, mortars blended with nanoparticles showed higher compressive strength with respect to the control sample. In this case, the addition of $\mathrm{TiO}_{2-x} \mathrm{~N}_{y}$ showed better results in comparison to $\mathrm{TiO}_{2}$. Some authors have mentioned that the addition of nanoparticles to the cement enhances the strength [32], possibly due to the important role of the nanoparticles in the hydration of the cement acting as nucleation sites. Additionally, nanoparticles are capable of sealing the pores creating a compact cementitious matrix, thus improving the mechanical behavior [33]. In this case, it is possible that nanoparticles with high surface area values do not improve significantly the compressive strength in mortars prepared with white Portland cement type I, because of they do not have the chemical composition to show pozzolanic activity.

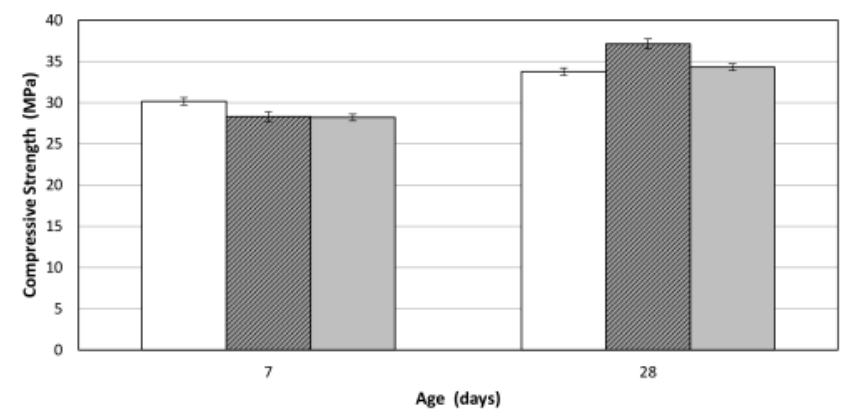

Figure 8 Compressive strength of samples after 7 and 28 days of curing age, $\square$ control sample, $\square 3 \% \mathrm{TiO}_{2-x} \mathrm{~N}_{\mathrm{y}}, \square 3 \% \mathrm{TiO}_{2}$. Error bars are standard deviation

\section{Conclusions}

The $\mathrm{TiO}_{2-x} \mathrm{~N}_{y}$ nanoparticles showed ability to be activated under UV-Vis irradiation. They also presented a positive effect on the development of compressive strength of mortars made with them. An energy band located above the valence band possibly induces the photocatalytic processes under visible light irradiation for $\mathrm{TiO}_{2-x} \mathrm{~N}_{\mathrm{y}}$.

The addition of $\mathrm{TiO}_{2-x} \mathrm{~N}_{y}$ nanoparticles to the cement is able to decompose organic compounds under UV-Vis irradiation. At early curing times (65 hours), the behavior under UV irradiation for $\mathrm{TiO}_{2}$ and $\mathrm{TiO}_{2-x} \mathrm{~N}_{y}$ was very similar, being $\mathrm{TiO}_{2}$ more effective in the abatement of the pigment. On the other hand, under visible light and 65 hours of curing time, the results were different. $\mathrm{TiO}_{2-x} \mathrm{~N}_{y}$ showed a high photoactivity especially with an addition percentage of $3 \%$ and $\mathrm{TiO}_{2}$ could not be activated. In this case, $\mathrm{TiO}_{2}$ showed a minimal abatement of Rhodamine $\mathrm{B}$ by physico-chemical phenomena, possibly due to a shielding effect, which prevents the photonic absorption in the dye.

After 28 days of curing time, a decrease in the photocatalytic efficiency was evidenced as result of the interaction between photocatalyst nanoparticles and hydrated products of the cement. However, under UV light 
irradiation, $\mathrm{TiO}_{2-x} \mathrm{~N}_{y}(3 \%)$ showed the highest photoactivity, proving the ability to absorb photons of low energy from the generation of photocatalytic reactions.

These nanoparticles, thanks to their physical characteristics, improved the compressive strength of the mortars blended to them even without having pozzolanic activity.

\section{Acknowledgments}

This work was supported by the "National program of projects for strengthening research, development and innovation in graduate 2014-2015" of the Universidad Nacional de Colombia.

\section{Conflicts of interest}

The authors declare no conflict of interest.

\section{References}

[1] A. Folli, U. Jakobsen, G. Guerrini, and D. Macphee, "Rhodamine B discolouration on $\mathrm{TiO}_{2}$ in the cement environment: A look at fundamental aspects of the self-cleaning effect in concretes", journal = "Journal of Advanced Oxidation Technologies," vol. 12, no. 5, November 30 2016. [Online]. Available: https://doi.org/10. 1515/jaots-2009-0116

[2] T. Maggos, J. Bartzis, M. Liakou, and C. Gobin, "Photocatalytic degradation of $\mathrm{NOx}$ gases using $\mathrm{TiO}_{2}$-containing paint: A real scale study," Journal of Hazardous Materials, vol. 146, no. 3, July 312007. [Online]. Available: https://doi.org/10.1016/j.jhazmat.2007.04.079

[3] T. S. Le and et al, "Photocatalytic equipment with nitrogen-doped titanium dioxide for air cleaning and disinfecting," Advances in Natural Sciences: Nanoscience and Nanotechnology, vol. 5, no. 1, February 28 2014. [Online]. Available: https://doi.org/10.1088\% 2F2043-6262\%2F5\%2F1\%2F015017

[4] L. Baltes, M. Patachia, O. Tierean, M. Ekincioglu, and M. Ozkul, "Photoactive polymer-cement composites for tannins removal from wastewaters," Journal of Environmental Chemical Engineering, vol. 5, no. 4, August 2018. [Online]. Available: https://doi.org/10.1016/j. jece.2018.06.039

[5] J. Gelves and et al, "Activity of an iron Colombian natural zeolite as potential geo-catalyst for NH3-SCR of NOx," Catalysis Today, vol. 320, January 15 2019. [Online]. Available: https: //doi.org/10.1016/j.cattod.2018.01.025

[6] V. Binas, K. Sambani, T. Maggos, A. Katsanaki, and G. Kiriakidis, "Synthesis and photocatalytic activity of Mn-doped $\mathrm{TiO}_{2}$ nanostructured powders under UV and visible light," Applied Catalysis B: Environmental, vol. 113-114, February 22 2012. [Online]. Available: https://doi.org/10.1016/j.apcatb.2011.11.021

[7] J. Cohen, G. Sierra, and J. Tobón, "Evaluation of Photocatalytic Properties of Portland Cement Blended with Titanium Oxynitride $\left(\mathrm{TiO}_{2}-\mathrm{xNy}\right)$ Nanoparticles," Coatings, vol. 5, no. 3, July 2015. [Online]. Available: https://doi.org/10.3390/coatings 5030465

[8] C. Cárdenas, J. Tobón, C. García, and J. Vila, "Functionalized building materials: Photocatalytic abatement of NOx by cement pastes blended with $\mathrm{TiO}_{2}$ nanoparticles," Construction and Building Materials, vol. 36, 2012. [Online]. Available: https://doi.org/10.1016/ j.conbuildmat.2012.06.017
[9] A. Strini, S. Cassese, and L. Schiavi, "Measurement of benzene, toluene, ethylbenzene and 0 -xylene gas phase photodegradation by titanium dioxide dispersed in cementitious materials using a mixed flow reactor," Applied Catalysis B: Environmental, vol. 61, no. 1-2, October 27 2005. [Online]. Available: https://doi.org/10.1016/j. apcatb.2005.04.009

[10] M. Diamanti, B. D. Curto, M. Ormellese, and M. Pedeferri, "Photocatalytic and self-cleaning activity of colored mortars containing $\mathrm{TiO}_{2}$," Construction and Building Materials, vol. 46, September 2013. [Online]. Available: https://doi.org/10.1016/j. conbuildmat.2013.04.038

[11] B. Ruot, A. Plassais, F. Olive, L. Guillot, and L. Bonafous, " $\mathrm{TiO}_{2}$-containing cement pastes and mortars: Measurements of the photocatalytic efficiency using a Rhodamine B-based colourimetric test," Solar Energy, vol. 83, no. 10, October 2009. [Online]. Available: https://doi.org/10.1016/j.solener.2009.05.017

[12] C. C. Ramirez, J. Tobón, and C. García, “Photocatalytic properties evaluation of Portland white cement added with $\mathrm{TiO}_{2}$-nanoparticles," Revista Latinoamericana de Metalurgia y Materiales, vol. 33, no. 2, pp. 316-322, Nov. 2013.

[13] R. Asahi, T. Morikawa, T. Ohwaki, K. Aoki, and Y. Taga, "Visible-light photocatalysis in nitrogen-doped titanium oxides," Science, vol. 293, no. 5528, July 13 2001. [Online]. Available: https://doi.org/10.1126/ science. 1061051

[14] C. D. Valentin and et al, "N-doped $\mathrm{TiO}_{2}$ : Theory and experiment," Chemical Physics, vol. 339, no. 1-3, October 15 2007. [Online]. Available: https://doi.org/10.1016/j.chemphys.2007.07.020

[15] M. Kitano, K. Funatsu, M. Matsuoka, M. Ueshima, and M. Anpo, "Preparation of nitrogen-substituted tio2 thin film photocatalysts by the radio frequency magnetron sputtering deposition method and their photocatalytic reactivity under visible light irradiation," The journal of Physical chemistry. B., vol. 110, no. 50, December 212006. [Online]. Available: https://doi.org/10.1021/jp064893e

[16] Y.Hong, C. Bang, D. Shin, and H. Uhm, "Band gap narrowing of $\mathrm{TiO}_{2}$ by nitrogen doping in atmospheric microwave plasma," Chemical Physics Letters, vol. 413, no. 4-6, September 26 2005. [Online]. Available: https://doi.org/10.1016/j.cplett.2005.08.027

[17] S. Yin and et al, "Synthesis of excellent visible-light responsive $\mathrm{TiO}_{2}-\mathrm{xNy}$ photocatalyst by a homogeneous precipitation-solvothermal process," Journal of Materials Chemistry, vol. 15, November 26 2005. [Online]. Available: https: //doi.org/10.1039/B413377C

[18] R. Amadelli, L. Samiolo, M. Borsa, M. Bellardita, and L. Palmisano, "N- $-\mathrm{TiO}_{2}$ Photocatalysts highly active under visible irradiation for NOx abatement and 2-propanol oxidation," Catalysis Today, vol. 206, May 1 2013. [Online]. Available: https://doi.org/10.1016/j.cattod. 2011.11.031

[19] M. Janus and et al, "Self-cleaning properties of cement plates loaded with N,C-modified $\mathrm{TiO}_{2}$ photocatalysts," Applied Surface Science, vol. 330, March 1 2015. [Online]. Available: https: //doi.org/10.1016/j.apsusc.2014.12.113

[20] M. Janus and et al, "Cementitious Plates Containing $\mathrm{TiO}_{2}-\mathrm{N}, \mathrm{C}$ Photocatalysts for NOx Degradation," Journal of Advanced Oxidation Technologies, vol. 18, no. 2, November 30 2016. [Online]. Available: https://doi.org/10.1515/jaots-2015-0207

[21] The maud program. Accessed may. 2015. [Online]. Available: https://bit.ly/2XnutP5

[22] N. Day. Departamento de química, Universidad de Cambridge. Accessed may. 2015. [Online]. Available: http://www. crystallography.net/cod/

[23] A. Yousefi, A. Allahverdi, and P. Hejazi, "Effective dispersion of nano- $\mathrm{TiO}_{2}$ powder for enhancement of photocatalytic properties in cement mixes," Construction and Building Materials, vol. 41, April 2013. [Online]. Available: https://doi.org/10.1016/j.conbuildmat. 2012.11.057

[24] Determinazione dell'attività fotocatalitica di leganti idraulici: Metodo della rodammina, UNI:Ente italiano di normazione. Milano, 2008.

[25] Standard Test Method for Compressive Strength of Hydraulic Cement Mortars, ASTM C109 / C109M - 16a, 2011.

[26] F. Billmeyer and M. Saltzman, Principles of Color Technology, 2nd ed. 
New York, USA: John Wiley \& Sons, 1981.

[27] R. Shannon, "Revised effective ionic radii and systematic studies of interatomie distances in halides and chaleogenide," Acta Crystallographica, vol. A 32, pp. 751-767, Mar. 1976.

[28] F. Chen, J. Zhao, and H. Hidaka, "Highly selective deethylation of rhodamine B: Adsorption and photooxidation pathways of the dye on the $\mathrm{TiO}_{2} / \mathrm{SiO}_{2}$ composite photocatalyst," International Journal of Photoenergy, vol. 5, no. 4, 2003. [Online]. Available: http://dx.doi.org/10.1155/S1110662X03000345

[29] G. Colón, S. Murcia, M. Hidalgo, and J. Navío, “Sunlight highly photoactive $\mathrm{Bi}_{2} \mathrm{WO}_{6}-\mathrm{TiO}_{2}$ heterostructures for Rhodamine $\mathrm{B}$ degradation," Chemical communications, vol. 46, no. 26, July 14 2010. [Online]. Available: http://dx.doi.org/10.1039/c0cc00058b

[30] L. Yang, A. Hakki, F. Wang, and D. Macphee, "Photocatalysis in cement-bonded building materials," Applied Catalysis B: Environmental, vol. 222, March 2018. [Online]. Available: https://doi.org/10.1016/j.apcatb.2017.10.013

[31] J.Chen, S. Kou, and C. Poon, "Photocatalytic cement-based materials: Comparison of nitrogen oxides and toluene removal potentials and evaluation of self-cleaning performance," Building and Environment, vol. 46, no. 9, September 2011. [Online]. Available: https://doi.org/10.1016/j.buildenv.2011.03.004

[32] J.Chen, S. Kou, and C. Poon, "Hydration and properties of nano- $\mathrm{TiO}_{2}$ blended cement composites," Cement and Concrete composite, vol. 34, no. 5, May 2012. [Online]. Available: https: //doi.org/10.1016/j.cemconcomp.2012.02.009

[33] J. Tobón, O. Restrepo, and J. Payá, "Portland cement blended with nanoparticles," DYNA, vol. 74, pp. 277-291, Jul. 2007. 